\title{
A totalidade cósmica em Maffesoli: Affaire Tremblay e franco-maçonaria
}

\section{Eduardo Portanova Barros}

Pós-doutor; PNPD/CAPES/PPG em Ciências Sociais/Universidade

do Vale do Rio dos Sinos

eduardoportanova@hotmail.com

MAFFESOLI, Michel. Le trésor

caché: lettre ouverte aux francs-maçons et à quelques autres. Paris, Éditions Léo Scheer, 2015

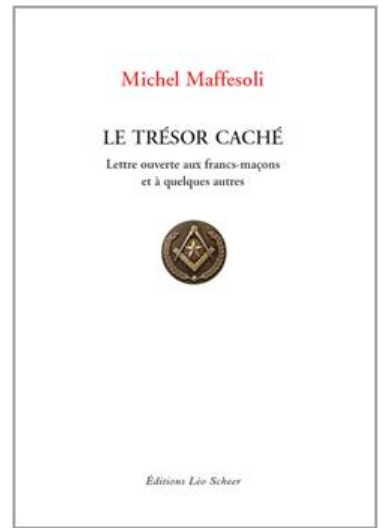

No dia 31 de março de 2015, depois de eu tomar conhecimento de um fato - que relatarei em seguida -, recebi na minha caixa postal uma mensagem de Michel Maffesoli, na qual ele anexava a cópia de uma entrevista que ele dera, por escrito, ao jornal Le Monde. Tratava-se (eis o fato) de uma farsa contra ele e a revista que dirigia - e que não dirige mais por esse motivo -, a Sociétés, fundada em 1982. 0 jornal queria saber, em três perguntas, o que ele tinha a dizer sobre um artigo fictício aceito pela revista "dele". 0 objetivo era "desmascará-lo" e isso logo depois veio a público pelos autores do texto, que usaram o pseudônimo J. P. Tremblay - por isso ficou conhecido na França, mas não por muita gente, como o Affaire Tremblay. "Nós criticamos sim uma perversão intelectual particular, o maffesolisme, ou seja, um grupo (tribo) marginal acadêmico liderado por uma concepção específica do homem e do mundo" 1 , justificaram, na seção de Ciências da edição on-line do Le Monde, do dia 27 de abril de 2015, os dois falsos autores, agora com seus nomes

\footnotetext{
1 No original: "Nous critiquions bien plutôt un dévoiement intellectuel particulier, le maffesolisme, c'est-à-dire une tribu académique marginale animée par une conception spécifique de l'homme et du monde". (QUINON, SAINT-MARTIN, 2015, documento eletrônico não paginado).
} 
verdadeiros: Manuel Quinon, doutorando em Sociologia na Universidade de Paris-Diderot, e Arnaud Saint-Martin, sociólogo e pesquisador do Centre National de la Recherche Scientifique (CNRS). 0 tema do artigo era o "autolib" (Automobilités postmodernes: quand l'Autolib' fait sensation à Paris), um pequeno carro de aluguel na França, que serviu de pretexto para fazerem a apologia, em tom de deboche, evidentemente, de uma "potência uterina" na pós-modernidade, entre outras coisas do gênero.

Esse episódio, que remete ao Caso Sokal e que não vale a pena relembrar, mas que, para quem nunca ouviu falar dele, fez o mesmo (os "Tremblay" não têm nem o mérito da originalidade), não prova nada. Só mostra o despeito por uma personalidade séria e condecorada na França e em outras universidades ao redor do mundo, que procura não seguir os métodos de um tradicionalismo doentio de cunho racionalista que sustenta sociólogos - alguns muito próximos do próprio Maffesoli, paradoxalmente - e outros ainda em formação, como Quinon, do qual poucos ouviram falar. 0 mesmo vale para Saint-Martin. E quando eu me refiro ao "tradicionalismo doentio", quero dizer: a disjunção binária e aristotélica entre as coisas do espírito e as coisas da matéria. Durand, a quem Maffesoli dedica o livro objeto dessa resenha, e merecidamente, pois ele escreveu, anteriormente, Les mythes fondateurs de la franc-maçonnerie (2005), foi, certamente, a inspiração de Maffesoli para este Le trésor caché: lettre ouverte aux francs-maçons et à quelques autres (2015). 0 "escondido" ("caché"), diferentemente do que se viu nesse antiético Affaire Tremblay, é de outra natureza, a de um pluralismo metodológico, algo que os "Tremblay", provavelmente, desconhecem. Este "Trésor caché”, o mais recente livro de Maffesoli, ainda só disponível na França, segue seu estilo ensaístico e anárquico, metodologicamente falando. Se em $A$ república dos bons sentimentos (2009) Teixeira Coelho disse que ali se tratava de um Maffesoli diferente, neste Trésor caché, não: Maffesoli é o mesmo.

O que quer dizer o mesmo em se tratando de Maffesoli? Por exemplo: um dos aspectos que ele salienta no texto é a questão da harmonia conflitual (p. 35), já abordada em obras anteriores, como Elogio da razão sensível (1998). Diz ele que se trata de uma característica maçônica esse "juste milieu": nem revolucionária, nem conservadora. Essa expressão "harmonia conflitual" nos remete à questão do pluralismo, em Durand, pelo fato de que "[...] repudia as soluções fáceis dos totalitarismos monistas ou unitários tão na moda no último 
século"2 (2003, p. 218). Durand aborda, no capítulo A ética do pluralismo, em Structures (2003), o princípio da "coincidentia oppositorum". Ora, esse princípio assemelha-se ao "juste milieu" de Maffesoli, no sentido de rechaçar a lógica dualista como verdade epistêmica. 0 tema do pluralismo, aliás, é um dos capítulos de $O$ conhecimento comum (2007) e que Maffesoli relaciona ao politeísmo de valores e à Sociologia Compreensiva em Max Weber (1864-1920). Weber dava ênfase, por exemplo, ao líder carismático, porque percebe que nos seus movimentos entusiásticos o status dá lugar à fraternização e aos sentimentos de comunidade. Este conceito de personalidade, segundo Weber, tem um centro de criatividade profundamente não racional (da mesma forma que a maçonaria, diria eu). Daí a análise weberiana das motivações "compreensivas" do indivíduo isolado, reduzindo termos genéricos como Estado, associação, entre outros, à ação "compreensível" dos atores sociais participantes. A maçonaria, ainda, nos termos em que Maffesoli coloca, poderia ser comparável ao que Max Weber expressa em seu conceito de "ideal tipo", que é a construção de uma utopia, acentuando alguns elementos da realidade. É exatamente nisso que se encaixaria a maçonaria no sentido de uma "totalidade cósmica".

Este Trésor caché, dentro dessa leitura compreensiva, é uma tese sobre o relativismo. Um dos grandes pensadores do relativismo, o físico austríaco Paul Feyerabend (1993), relata que não é totalmente contra o cartesianismo e outras doutrinas do gênero excludente das partes, e sim o fato de que isso é tomado como a única verdade, e essa única verdade acaba tomando, também, um rumo demasiado sociologizante (ou outro tema qualquer), esquecendo-se que isso se forma a partir do "Outro" e que existe, nessa relação, um terceiro (nesse caso, excluído). "A história da ciência, bem vistas as coisas, não consiste apenas em fatos e em conclusões extraídas dos fatos. Contém também ideias, interpretações dos fatos, problemas criados por interpretações conflituais, erros, e assim por diante". (FEYERABEND, 1993, p. 25). Durand (2003), por sua vez, afirma que o Ocidente tem uma personalidade de base disjuntiva. Segundo ele, nós dissociamos o espírito individual da realidade pensante no geral. São contradições semânticas que os gregos pré-socráticos, por exemplo, não tinham. 0 grego tinha o dom da nuance, salienta Durand (2003). Forma era morphé, schéma, ousia e eidos. Aos poucos, porém, inclusive com o grego clássico, se passou para uma simplificação

\footnotetext{
2 Durand se referia ao século XIX, pois sua palestra no Círculo de Éranos, na Suíça, ocorrera em 1975, quando se comemorou o centenário de nascimento de C. G. Jung, a quem Durand dedicou sua apresentação, naquela ocasião, intitulada $L$ 'éthique du pluralisme et le problème de la cohérence. Pour le centenaire de la naissance de Jung. Trecho original: “[...] a répudié les solutions faciles des totalitarismes monistes ou unitaires si à la mode au siècle dernier" (tradução nossa). 0 prefácio do livro no qual aparece o capítulo de Durand sobre o pluralismo, aliás, é de Michel Maffesoli, no qual destaca que os encontros de Éranos, e não muito diferentemente da totalidade cósmica da franco-maçonaria, nós poderíamos acrescentar, está em sintonia com a intemporalidade do mito (o illud tempus).
} 
sintática, e não mais se manteve uma complexidade semântica, de acordo com Durand (2003). Termos gregos, continua o autor, no final das contas, recobrem as duas acepções contraditórias da forma: aparência e sentido. 0 livro de Maffesoli, na esteira de Durand, faz menção aos mitos. Porém, não se trata de um estudo de viés mitológico como no trabalho de Eliade, por exemplo, outro frequentador de Éranos, além de Durand. E, apesar de Maffesoli ter, provavelmente, se inspirado no livro de Durand sobre os maçons, a metodologia é outra. Durand, diferentemente de uma Sociologia do Cotidiano, trata de uma arquetipologia por meio da mitocrítica. Guarda, porém, pelo menos uma semelhança com a Sociologia do Cotidiano, que é o pluralismo metodológico - como na ideia, por exemplo, do terceiro incluído (p. 185). Maffesoli simboliza essa noção com a Lei dos Irmãos (horizontal) e não com a Lei do Pai (vertical).

Em um artigo biográfico sobre Durand (2014), a pesquisadora Ana Taís Martins Portanova Barros ressalta que a mitocrítica dele a respeito do conde Joseph de Maistre (1753-1821), intitulada Um comte sous l'acacia (1999), “[...] preparou o terreno para sua próxima obra, 'Os mitos fundadores da franco-maçonaria', de 2002”. (2014, p. 154). Essa é a origem do livro de Maffesoli: Durand. 0 estilo é fenomenológico. Pouco se fala da possível relação de Maffesoli com Husserl, que introduziu o conceito de fenomenologia nas ciências no século XIX. Em Trésor caché, o que o interessa como proposta metodológica é não a coisa, mas o fenômeno. Para Husserl, justamente, “A fenomenologia transcendental não será fundada como ciência de fatos, mas como ciência de essências (ciência eidética), que pretende esclarecer exclusivamente conhecimentos de essência e de modo algum fatos". (2006, p. 28). A maçonaria sob o viés maffesoliano, pois, é - e aqui se encontra a fenomenologia em Husserl - uma diversificação na maneira de olhar.

Dois outros filósofos orientam, igualmente, Maffesoli. São eles: Heidegger, aluno de Husserl, por sinal, e Nietzsche, cuja relação eu já propus em Maffesoli: entre a ciência alegre e o demasiado humano. Aproximações de uma Sociologia Anarquista (2014), em coautoria com Rafael Rossetto. Não pretendo me alongar nesse aspecto, até porque já o tratei no livro mencionado, mas destacaria o seguinte: Nietzsche denunciou o conteúdo dialético em Sócrates, segundo o qual a alma teria de se refugiar no mundo da Razão. Para Nietzsche, no entanto, esse método socrático de convencer pela astúcia ou a procura natural da Verdade, é uma ilusão. "Com Sócrates, o gosto grego se altera em favor da dialética. Antes dele, a dialética era rejeitada e comprometedora. Desconfiava-se de toda essa exibição dos próprios motivos". (NIETSZCHE, 2006, p. 19). 
Temos, nesta breve síntese, um complexo de situações que nos remetem, pelo menos da forma como este Trésor caché orienta, ao contraponto - fortemente heideggeriano entre o ser e a máquina (no sentido da técnica). As fronteiras no vivido, entretanto, são fluidas. Se tomarmos - e este é o caminho de Maffesoli - a perspectiva do imaginário cotidiano, segundo o qual a cultura - como um constructo - não se aparta das pulsões, considerando-as aqui como motivações inerentes ao ser, poderíamos trabalhar com a ideia de polaridades. Esta também é a ideia das "constelações metafóricas". Trata-se, na verdade, quanto à natureza epistemológica adotada por Maffesoli, da procura de uma abordagem por aproximações e de modo, na medida do possível, compreensivo. Polaridades, e isso também precisa ficar muito claro, não são, da forma como nós interpretamos, dicotomias. São polos ao mesmo tempo antagônicos e complementares. A "totalidade cósmica" maçônica é uma dimensão qualitativa enraizada numa estrutura arquetípica. 0 propósito de Maffesoli não é desvendá-la, mas, sim, matizá-la. Ao fazer isso, ele procura considerar a relação entre o ser e a estrutura, como esse trajeto que se faz entre o coercitivo e o pulsional, bebendo no que Durand (1997) denomina "trajeto antropológico". O arquétipo, conforme a Psicologia das Profundezas, situa-se exatamente aí, em "[...] formas arcaicas restituídas à vida". (JUNG, p. 13, 2007). Com isso, queremos dizer que Trésor caché não pode ser interpretado apenas sob um ponto de vista racional. Nele e dele emerge o conflito do si-mesmo. O que Maffesoli salienta permanece nesse viés, metodologicamente falando, de uma sociologia fenomenológica e compreensiva. Também percebem-se ressonâncias simmelianas (as de um pragmatismo cotidiano), além de weberianas, como eu já destaquei antes, no sentido de considerar as não racionalidades (a relação, por exemplo, entre forças coercitivas, oriundas da construção social, e pulsionais, entranhadas no humano ser).

Em Hjelmslev, para terminar, constelação significa: “[...] uma totalidade que não se compõe de objetos, mas sim de dependências, e que não é sua substância [...]" (2013, p. 28). Sabemos, com Heidegger, que existe um conflito de base - e que, para Nietzsche, isso se traduziria em tragédia, enquanto, para Durand, em "trajeto antropológico" - próprio de todo relativismo, que é o da diferenciação complementar entre o "ser-aí" heideggeriano. Voltamos aos polos dialógicos referidos anteriormente entre a subjetividade do ser e o aí da construção tecnológica como força coercitiva. $O$ vivido não é perfeito. A complexidade não é perfeita. 0 trágico não é perfeito. 0 indivíduo esfacela-se em múltiplos papéis porque ele não se reconhece mais uno. Esse é o sentimento niilista, o de que nada mais é. E, assim como na filosofia, que, conforme Vattimo (1996), tem por objetivo negar as estruturas estáveis do 
ser, este Trésor caché do qual falamos consiste, além de outras leituras possíveis, em uma crítica à crença, ainda presente, na invariabilidade dos costumes, no "habitus" que ancora hoje não mais - a pessoa a alguma coisa. Crítica porque, ao contrário do "habitus", da fixação, a ciência tem uma natureza entrópica: aquilo que nasce também morre. Mas no Affaire Tremblay foi o inverso: neste caso, já estava morto antes de nascer.

\section{Referências}

BARROS, E. P; ROSSETTO, R. Maffesoli: entre a ciência alegre e o demasiado humano. Aproximações de uma Sociologia Anarquista. São Leopoldo: Oikos, 2014. 141 p.

BARROS, A. T. M. P. Gilbert Durand, o montanhês que desafiou a margem esquerda do Sena. Esferas, Brasília, v. 3, n. 4, p. 147-155, jan./jun. 2014.

DURAND, G. Les mythes fondateurs de la franc-maçonnerie. Paris: Éditions Dervy, 2005. $166 \mathrm{p}$.

DURAND, G. Structures: Éranos I. Paris: La Table Ronde, 2003. 347 p.

DURAND, G. As estruturas antropológicas do imaginário: introdução à arquetipologia geral. São Paulo: Martins Fontes, 1997. 551 p.

FEYERABEND, P. Contra o método. Lisboa: Relógio D’Água, 1993. 364 p.

HJELMSLEV, L. Prolegômenos a uma teoria da linguagem. São Paulo: Perspectiva, 2013. $147 \mathrm{p}$.

HUSSERL, E. Ideias para uma fenomenologia pura e para uma filosofia

fenomenológica: introdução geral à fenomenologia pura. Aparecida: Ideias \& Letras, 2006. $383 \mathrm{p}$.

JUNG, G.C. 0 eu e o inconsciente. Petrópolis: Vozes, 2007. 166 p.

MAFFESOLI, M. A república dos bons sentimentos. São Paulo: Iluminuras, 2009. 96 p.

MAFFESOLI, M. O conhecimento comum: introdução à Sociologia Compreensiva. Porto Alegre: Sulina, 2007. 295 p.

MAFFESOLI, M. Le trésor caché: lettre ouverte aux francs-maçons et à quelques autres. Paris: Éditions Léo Scheer, 2015. 192 p.

MAFFESOLI, M. Elogio da razão sensível. Petrópolis: Vozes, 1998. 207 p.

NIETZSCHE, F. Crepúsculo dos ídolos: ou como se filosofa com o martelo. São Paulo: Companhia das Letras, 2006. 154 p. 
QUINON, Manuel; SAINT-MARTIN, Arnaud. Um canular sociologique, et après ? $27 \mathrm{abr}$. 2015. Disponível em <http://www.lemonde.fr/sciences/article/2015/04/27/un-canularsociologique-et-apres_4623682_1650684.html>. Acesso em: 13 maio 2015.

VATTIMO, G. 0 fim da modernidade: niilismo e hermenêutica na cultura pós-moderna. São Paulo: Martins Fontes, 2002. 208 p.

Recebido em 11/05/2015

Aceito em 20/05/2015 